\title{
REFLEXÕES SOBRE A DOCÊNCIA DE ENFERMAGEM EM UMA UNIVERSIDADE PÚBLICA
}

\author{
REFLECTIONS ABOUT THE FACULTY MEMBER \\ IN A NURSING SCHOOL OF A PUBLIC UNIVERSITY
}

Miriam Aparecida Barbosa Merighi*

MERIGHI. M.A.B. Reflexøes sobre a docência de enfermagem em uma universidade pública. Rev.Esc.Enf.USP, v.32, n.1, p. $80-3$, abr. 1998 .

\section{RESUMO}

É discutido o papel do docente de enfermagem que trabalha em Escola de Enfermagem vinculada à Universidade Pública, numa tentativa de propor estratégias de integração entre ensino-pesquisa e assistência e, consequentemente beneficios para os próprios docentes, para a escola de enfermagem e para a profissão.

UNITERMOS: Docência de enfermagem.Escola de enfermagem

\begin{abstract}
This article is about the discussion. on the faculty member's role, who are working in a Nursing School of a Public University, attempting to suggest integration strategies to teach and research about the nursing and the care of people, and consequently the benefits to the teachers, to the nursing school and to the nursing profession.
\end{abstract}

UNITERMS : Faculty member.Nursing school

\section{INTRODUÇÃO}

Repensando as inúmeras atividades realizadas pelos docentes de enfermagem que trabalham em uma Universidade Pública realizei este estudo com o intuito de sugerir estratégias para que, através do ensino de enfermagem, possa contribuir, de forma efetiva, para a formação dos enfermeiros e consequentemente influenciar na melhoria da assistência ao paciente.

Considero que a especificidade das ações desenvolvidas no ensino de enfermagem é um fator que dificulta a conciliação das atividades que devem ser exercidas por um docente em Universidade Pública, pois a característica teórico-prática do ensino em enfermagem requer acompanhamento direto do aluno por parte do docente, exigindo supervisão individualizada e permanente
Durante vinte anos como docente de uma Escola de Enfermagem, vinculada a uma Universidacle Pública, acreditei que o ensino de enfermagem deveria estar fundamentado na cooperação entre escola e serviço, tendo ambos a finalidade de favorecer a melhoria da qualidade da assistência prestada à clientela e fornecer contínuo embasamento para transformação e adequação do ensino e da prática.

No entanto, o vivencial do trabalho docente na Escola de Enfermagem provoca, em mim, inquietação, devido às inúmeras atividades burocráticas que o deve desenvolver. Essas atividades ocupam inúmeras horas semanais com reuniões o representações do grupo disciplinar em colegiados, comissões e subcomissões. Somadas a

\footnotetext{
Enfermeira. Doutor do Departamento de Enfermagem Materno-Infantil e Psiquiátrica da Escola de Enfermagem da Universidade de São Paulo.
} 
essas atividades estão as exigências de produção científica da participação e apresentação de trabalhos em eventos científicos e em cursar programas de Pós-Graduação e assim desenvolver a carreira universitária. A tudo isto. deve-se acrescentar as atividades particulares, de mãe, de esposa e de dona de casa.

Os anos de vivência na docência de enfermagem intensificaram cada vez mais estas minhas inquietações. Acredito que todas estas atividades são necessárias, mas como conciliá-las? Penso que são tarefas gigantescas para que uma pessoa possa realizar concomitantemente. Como executá-las de forma eqüitativa?

Existem aspectos na atuação docente, que por não se mostrarem claros, provocam incertezas. O que está oculto exige um interrogar mais atento e rigoroso, levando à necessidade de se tematizar os elementos constitutivos da fonte de inquietações que, para mim, manifestaram-se da seguinte forma: como o desempenho destes papéis repercute no aluno, na equipe assistencial, na Instituição de ensino e no próprio docente? Será que esse total de atividades, bem como as exigências de títulos acadêmicos podem se tornar um empecilho para o ensino, ou um transtorno na carreira docente? Estaria a consecução do cumprimento dessas exigências determinando projeção pessoal e acadêmica em detrimento e desvalorização da atividade docente? Neste contexto, como o docente faria para integrar a assistência e a docência sem ampliar a distância entre a teoria e a prática?

\section{REVISÃO DA LITERATURA}

É significativa a quantidade de artigos publicados que se referem à dicotomia existente entre o ensino e a assistência e à docência de enfermagem de antigamente e a atual. Ressaltam que antes a docente de enfermagem concentrava suas ações nas tarefas assistenciais, era vista e respeitada como aquela que sabia cuidar do paciente. Posteriormente, a enfermagem tornou-se uma carreira universitária e a pesquisa passou a ser imprescindível. Com esta evolução, o docente passou a enfrentar o problema de ter que conhecer a teoria, de ter vivência da prática, embora deixando de desenvolver uma atividade contínua no campo. Passou a ser vista pelo aluno como aquela que conhece a teoria e é respeitada pelo seu saber, enquanto o enfermeiro assistencial é o modelo da capacidade técnica, é o que sabe fazer.

A grande queixa dos enfermeiros é que a teoria nem sempre se aplica a prática profissional. Os docentes de enfermagem são rotulados de teóricos, fora da realidade profissional e o trabalho dos enfermeiros de campo é classificado como "rotineiro". A grande queixa dos docentes é que não é possível melhorar o ensino sem boa qualidade do cuidado de enfermagem. Este fato traz conseqüências graves para a enfermagem como profissão: desprestígio e vulnerabilidade causadas pela situação conflitiva entre ensino e assistência (RIBEIRO, 1970; CIETTO; PEREIRA, 1981; MINZONI, 1983; SATI, 1984).

FRANÇA (1989) comenta sobre as exigências e distorções da carreia universitária. Exigências no sentido de que é necessário titular-se como mestre, doutor, livre docente e titular, demonstrar produção intelectual formalizada em artigos e/ou em livros, pesquisar, participar de eventos, assumir funções administrativas. Distorções no sentido de que todas essas exigências podem tornar a atividade docente, o dar aula, um empecilho, um transtorno na carreira do professor. Ainda, segundo o mesmo autor, o nível ou a qualidade das aulas ministradas não são questionados pela Universidade.

ALMEIDA (1985) também faz comentários sobre a produção científica dos docentes de enfermagem. Afirma que estes vêm pensando a enfermagem de um modo abstrato e idealista, o que encobre as contradições verificadas na prática. Esta, como resultado da ação das enfermeiras docentes, tenta ser carregada de intelectualização e cientifização, direcionada pela sua produção cientifica voltada para a assistência de enfermagem. No entanto essa não é sua prática, o que delinea, portanto, um discurso ideologizado, deslocado da prática, e além do mais, centrado num homem biopsico-social abstrato. Evidencia-se, assim, a necessidade de serem reconstruídos modelos de investigação, pois os atuais não atendem nem ao próprio trabalho docente.

JOACHIM (1988) comenta os dilemas que envolvem os docentes de enfermagem nos Estados Unidos em relação a seus diferentes papéis. Uma atividade freqüentemente ausente é a prática da profissão, enquanto enfermeiro, nos seus aspectos técnicos. Reforça, também, que esta ausência gera grande dificuldade em encontrar questões para pesquisar, uma vez que o docente não está vivenciando a realidade da prática. Afirma que os enfermeiros compõem um dos únicos grupos docentes de universidade que vivem esta dissociação, e faz o seguinte questionamento: existem médicos, dentistas, arquitetos que ensinam e não têm prática? Esses profissionais têm como fonte de renda predominante, o exercício profissional, sendo a docência um complemento; na enfermagem ocorre o oposto, pois em geral, o professor recebe salário maior que o enfermeiro assistencial. 
Ainda, conforme JOACHIM (1988), docentes de enfermagem freqüentemente questionam a qualidade da assistência, considerando-a inadequada; pesquisam sobre o assunto, mas os resultados não retornam para a prática, não contribuindo assim para a mudança da assistência. Esses fatos, na realidade, constituem verdadeiro dilema pois o domínio da prática assistencial não é necessário para a sobrevivência do docente na universidade, nem para o seu progresso na carreira. Outro aspecto mencionado, pelo mesmo autor, é que o título de docente de enfermagem ajuda o profissional a obter "status", enquanto o título de enfermeiro diminui sua auto-imagem. Por esse motivo, o docente distancia-se da prática e permanece exclusivamente dentro da universidade.

JOEL (1985) afirma que a magnitude da importância do ensino teórico-prático na enfermagem deveria fazer com que este fizesse parte dos critérios para promoção e avaliação do profissional na universidade. Esta precisa convencer-se da importância da prática clínica para os docentes em uma profissão que é tanto acadêmica como praticamente orientada.

\section{VISLUMBRANDO UM CAMINHO}

Estar consciente do que é ser docente de enfermagem em uma universidade pública significa fazer algo em relação a isso.

Tenho preocupação cada vez maior em discutir o ensino e, em especial, a graduação. O currículo vigente está construído e cabe ao professor executálo. Assim, romper com este modelo abstrato, teórico, neutro, reprodutivo, e construir um currículo identificado com a realidade, resgatando a cultura de que os alunos são portadores, torna-se uma tarefa de resistência à reprodução (SILVA, 1990).

Considero também, importante, repensar o ensino de Pós-Graduação no que concerne ao seu papel e compromisso com o desenvolvimento científico e autonomia da profissão. Que contribuição a Pós-Graduação poderia proporcionar para a saúde da população? Qual tem sido sua repercussão para a formação na graduação?

Vejo ainda, a necessidade de discutir sobre as atividades burocrático-administrativas exercidas pelos docentes de enfermagem, com as inúmeras reuniões das quais participam que, podem tornarse desgastantes. Precisamos encontrar estratégias para que nossas reuniões sejam mais objetivas, conseqüentemente mais produtivas e eficazes. Dessa forma haveria um possivel equilíbrio entre as várias atividades da atuação docente.
E a nossa produção científica? A quem está satisfazendo? $O$ que o docente de enfermagem deveria investigar? Seria voltada ao ensino, à assistência, aos processos de ensino e assistência, de modo que cada um reflita na qualidade do outro?

Existem espaços vazios entre o ensino, a assistência e a pesquisa. Como já foi apresentado na introdução deste texto, docentes de enfermagem, em uma Universidade, assumem diversas atividades: ensinam conceitos de enfermagem aos alunos, supervisionam a aplicação destes conceitos nos campos de conhecimento em enfermagem e disseminam os resultados através de publicações; prestam serviço à comunidade na forma de educação para a saúde e de consultoria; precisam de preparo, titulação em Pós-Graduação e produtividade científica.

Diante dessas considerações tenho os seguintes questionamentos: como é possivel ter questões para pesquisar e encontrar resultados úteis para a prática sem estar vivenciando a realidade da assistência? É possível prestar serviço relevante à comunidade sem esta prática assistencial? É possível ter credibilidade como docente de enfermagem sem ter habilidade técnica? Sem o desenvolvimento da prática da profissão? Estarão os professores de enfermagem e a profissão de enfermagem modificando-se devido à falta de envolvimento com a prática?

Vários artigos comentam a dicotomia existente entre educação e serviço (DUFFY, 1986; INFANTE, 1986; DENYES, 1989; CAVE, 1994; KOPALA, 1994). Salientam que a ausência da prática dos docentes de enfermagem traz algumas conseqüencias, tanto para a profissão como para o paciente. Afirmam que os educadores devem trabalhar com seus colegas de profissão para desenvolverem, conjuntamente, estratégias que aumentem a qualidade da assistência, promovendo uma satisfação na profissão e estimulando experiências de aprendizado. Trabalhar junto reforça um ao outro. $O$ docente de enfermagem pode constatar que a qualidade da assistência é inadequada, mas, vivenciando os campos de prática somente no período de estágio não toma decisões, nem assume responsabilidades nessa assistência. Os autores mencionam, ainda, que aqueles que têm grande conhecimento teórico para fazer uma mudança planejada não a fazem, com isso a assistência ao paciente fica prejudicada.

Para influenciar e contribuir na melhoria da assistência ao paciente, o docente de enfermagem precisa fazer-se presente e conseguir credibilidade entre a equipe de saúde.

Quando os docentes de enfermagem não atuam junto à equipe de campo, os resultados da pesquisa dificilmente retornam para a prática institucional 
e, consequentemente, não mudam a assistência Portanto, realizar pesquisa junto com os enfermeiros assistenciais é uma oportunidade para estes publicarem, pois poucos enfermeiros têm publicações de pesquisa; esse procedimento facilita a implementação dos resultados e conseqüentemente melhora a assistência.

Percebo que existem obstáculos que tendem a perpetuar a dissociação entre a teoria e a prática de enfermagem. Considero que as exigências impostas pelo regimento da universidade fazem com que a sobrevivência, a promoção e a permanência do docente dentro desta seja alcançada pela ascensão na carreira. Torna-se claro um dos aspectos da dicotomia, pois se a prática não é uma atividade necessária para a sobrevivência dentro do sistema acadêmico e os docentes desejam permanecer nesse estágio, então, a tendência é direcionar suas forças para progredir na carreira afastando-se, assim, da prática e do ensino de graduação. Dentro de um sistema que não prevê e promove a prática assistencial, não há tempo disponível para esta.

Acredito que uma das estratégias que permita aos docentes a realização simultânea do ensino, da assistência e da pesquisa seja a articulação escola e serviço. Com isso há benefícios para os próprios docentes, que estariam integrados no campo ensinado e o utilizando para a pesquisa; para a instituição e para a própria profissão. Contudo, a escola, como um todo, deveria participar deste intercâmbio com os serviços de saúde, pois se as tentativas forem individuais, o docente acaba sendo absorvido pela instituição, desvinculando-se da sua função educadora, voltando-se totalmente para a assistência e terminando por prejudicar seu desempenho acadêmico.

Mudanças precisam ocorrer. Os docentes de enfermagem precisam assistir, ensinar e pesquisar simultaneamente. A competência do cuidar adquirirse cuidando e pesquisando. Ao invés de pesquisar para cuidar, devemos, enquanto enfermeiros. docentes, cuidar e pesquisar, assim estaremos inquirindo enquanto pesquisadores, cuidando enquanto enfermeiros e ensinando enquanto educadores. Acredito que ao integrarmos esses três aspectos das nossas atividades, conseguiremos a valorização, pela universidade, do ensino teóricoprático, sem perder a nossa especificidade.

Este artigo, sobretudo, procurou oferecer ao docente de enfermagem a possibilidade de refletir sobre o seu "modo de ser", sobre o cotidiano de sua prática, no sentido de compreender a situação relacionada com os profissionais que está formando.

\section{REFERÊNCIAS BIBLIOGRÁFICAS}

ALMEIDA, M.C.P. A prática de enfermagem como subsídio para a formaçăo do enfermeiro. In: SEMINÁRIO A PRÁTICA DE ENFERMAGEM E O CURRICULO DE GRADUAÇÃO, 1. Ribeirao Preto, 1985. Anais RibeirãoPreto, Escola de Enfermagem de Ribeirăo Preto da USP, 1985. p. 53-9.

CAVE, I. Nurse teachers in higher education without clinical competence, do they have a future? Nurse Educ. Today, v.14, n.5 p. 394-9, 1994.

CIETTO, L.; PEREIRA, D.M.S. Integração da assistencia e do ensino de enfermagem: considerações sobre aspectos organizacionais e administrativos. Rev. Bras. Enf., v.34, n.1, p.41-7, 1981 .

DENYES, M.J. et al. Integration nursing theory, practice and research though collaborative research. J.Adv.Nurs., v. 14, n.1, p. 141-5, 1989 .

DUFFY, D.M.; HALLORAN, C.S. Meeting the chaleng of multiple academic roles though a nursing center practice model. J. Nurs. Educ., v.25, n.2, p.55-8, 1986.

FRANÇA, C. Psicologia fenomenológica: uma das maneira de fazer. Campinas, Unicamp, 1989.

INFANTE, M.S. The conflicting roles of nurse and educators. Nurs. Outlook, v.34, n.2, p.94-6, 1986.

JOACHIM, G. Faculty practice: dilemas and solutions J.Adv.Nurs., v.13, n.3, p. 410-5, 1988.

JOEL, L. The rutgers experience: one perspective on serviceeducation collaboration. Nurs.Outlook, v.33, n.1, p.221-4, 1985 .

KOPALA, B. Conflict in nurse educatior's role oblgations. J. Prof. Nurs., v. 10, n.4, p. 236-43, 1994.

MINZONI, M.A. Alguns aspectos da integraçáo docente assistencial. Rev. Paul. Enf., v.3, n.4, p.137-9, 1983.

RIBEIRO, C.M. Novas tendências no ensino e na prática de enfermagem. Rev. Esc. Enf. USP, v.4, n.1/2, p.21-39, 1970.

SANTI, M.C. Revelando a dimensão educadora do professor de enfermagem. São Paulo, 1984. 87 p. Dissertação (Mestrado). Pontífica Universidade Católica de São Paulo.

SILVA, J.M.N. A construção do currículo na sala de aula: o professor como pesquisador. São Paulo, EPU, 1990. 